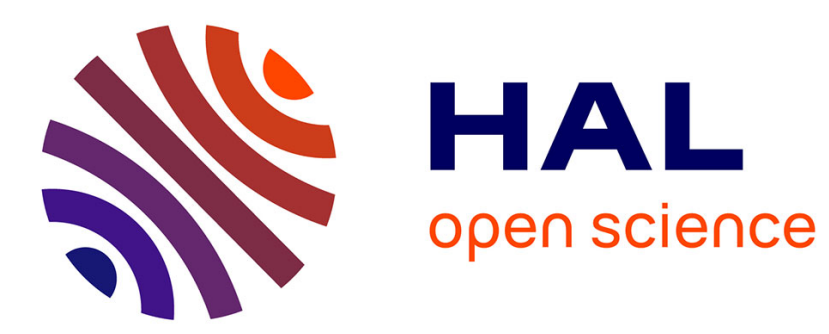

\title{
Ports in multi-level maritime networks: Evidence from the Atlantic (1996-2006)
}

César Ducruet, Céline Rozenblat, Faraz Zaidi

\section{To cite this version:}

César Ducruet, Céline Rozenblat, Faraz Zaidi. Ports in multi-level maritime networks: Evidence from the Atlantic (1996-2006): evidence from the Atlantic (1996-2006). Journal of Transport Geography, 2010, 18 (4), pp.508-518. 10.1016/j.jtrangeo.2010.03.005 . halshs-00466163

\section{HAL Id: halshs-00466163 \\ https://shs.hal.science/halshs-00466163}

Submitted on 22 Mar 2010

HAL is a multi-disciplinary open access archive for the deposit and dissemination of scientific research documents, whether they are published or not. The documents may come from teaching and research institutions in France or abroad, or from public or private research centers.
L'archive ouverte pluridisciplinaire HAL, est destinée au dépôt et à la diffusion de documents scientifiques de niveau recherche, publiés ou non, émanant des établissements d'enseignement et de recherche français ou étrangers, des laboratoires publics ou privés. 


\title{
Ports in multi-level maritime networks: evidence from the \\ Atlantic (1996-2006)
}

Journal of Transport Geography, in press

\author{
César DUCRUET ${ }^{1}$ \\ Centre National de la Recherche Scientifique (CNRS) \\ University of Paris-I Panthéon Sorbonne \\ UMR 8504 Géographie-Cités / P.A.R.I.S. \\ 13 rue du Four \\ F-75006 Paris \\ France \\ Tel. +33 (0)140-464-007 \\ Fax $+33(0) 140-464-009$ \\ Email: ducruet@parisgeo.cnrs.fr \\ Céline ROZENBLAT \\ University of Lausanne \\ Faculty of Geosciences and Environment \\ Institute of Geography (IGUL) \\ Quartier UNIL-Dorigny, Bâtiment Anthropole \\ CH-1015 Lausanne \\ Switzerland \\ Email: celine.rozenblat@unil.ch
}

Faraz ZAIDI

University of Bordeaux I

CNRS UMR 5800

Laboratory of Bordeaux for Research in Computer Science (LABRI)

351 Cours de la Libération

F-33405 Talence Cedex

France

Email: faraz.zaidi@1abri.fr

\footnotetext{
${ }^{1}$ Corresponding author
} 


\title{
Ports in multi-level maritime networks: evidence from the Atlantic (1996-2006)
}

\begin{abstract}
While maritime transport ensures about $90 \%$ of world trade volumes, it has not yet attracted as much attention as other transport systems from a graph perspective. As a result, the relative situation and the evolution of seaports within maritime networks are not well understood. This paper wishes verifying to what extent the hub-and-spoke strategies of ports and ocean carriers have modified the structure of a maritime network, based on the Atlantic case. We apply graph measures and clustering methods on liner movements in 1996 and 2006. The methodology also underlines which ports are increasing their position by carriers' circulation patterns on various scales. This research demonstrates that the polarization of the Atlantic network by few dominant ports occurs in parallel with the increased spatial integration of this area by shipping lines.
\end{abstract}

Keywords: Clustering methods; Graph visualization; Liner shipping; Port hierarchy; Scalefree network 


\section{Introduction}

The very essence of seaports is to link maritime networks and land networks (Weigend, 1958; Vigarié, 1968). Technological improvements (e.g. containerization, and economies of scale) and the integration v/s disintegration of firms (e.g. vertical and horizontal) have had economic impacts on port pricing, service quality, and frequency (Notteboom, 2004), resulting in fierce competition to catch evermore traffic. Such trends were observed by numerous scholars, notably through their geographic impact in terms of evolving port hierarchies of traffic concentration and of uneven distribution of port calls. However, the relative situation of seaports within maritime networks is not well understood, notably due to the limited methodology applied to maritime transport networks.

This paper wishes to apply new techniques of graph analysis to Atlantic liner shipping networks using new concepts based on "small worlds" (Watts, 1998) or on "scale free networks" (Barabasi, Albert, 1999), and new tools dedicated to analyze graphs ${ }^{2}$. This need of new concepts and tools draws upon recent research about containerization in the Atlantic. For instance, Slack (1999), discussing the reorganization of Atlantic liner networks with a global focus, or other regional studies, confirm one common trend: the simplification of the geographical coverage of shipping lines resulting from hub-and-spoke strategies. We can assume that maritime networks generate "small worlds" which content may vary over space and time under the influence of trade and carrier patterns, while in port and maritime geography, such spatial units are not well defined and delimitated, such as port region, port system, port range or maritime façade. Such dynamics may vary in amplitude depending on the region: the North Atlantic is more a direct call region (Helmick, 1994; Rowlinson, 1999; Gilman, 1999) and the Caribbean basin has become a hub port region (McCalla et al., 2005; McCalla, 2008). Other studies are more focussed on port selection and competition notably along the North-eastern seaboard (McCalla, 1999; Rodrigue and Guan, 2009) and through the comparison of traffic concentration trends in Europe and between various regions (Notteboom, 2006). Hereby, hierarchical processes seem to occur and could be measured by a scale free approach. This Atlantic region taken as a whole including the African and Latin American coasts has been paid little attention, and this research shall test its relevance.

\footnotetext{
${ }^{2}$ We used TULIP software created by the Laboratoire Bordelais de Recherche en Informatique (LABRI), and which was initially created for biology. It is today extensively used for social network analysis and in transport studies notably on air transport networks, intra and inter-urban commuter flows, and multinational corporations' networks in the SPANGEO project (http://s4.csregistry.org/SpanGeo). The TULIP software is free, open source and available at: http://tulip.labri.fr/
} 
The main issue expressed in the research on the Atlantic is the reorientation of liner network services through the rationalization strategies of ocean carriers on an intercontinental level. This occurs mostly as a response to increased globalization, and economic growth in the Asia-Pacific and Latin America regions (Slack, 1999). Many direct relations between European and US East coast ports were rerouted for transhipment in the Caribbean, symbolizing less the success of practical arrangements (carriers, hub ports) than the impact of trade growth on the shift of the ocean's centre of gravity from North to Mid-Atlantic. Evidence is given by Starr (1994) and Marcadon (1999) about the lower growth of New York and Montreal compared with southern ports such as Hampton Roads and Miami in recent years. In the South Atlantic, direct calls rather than feeder services have been implemented by shipping lines in the late 1990s so as to support growing North-South American trades (Guy, 2003). Some major shipping lines bypass Suez Canal by deviating along the Cape of Good Hope, such as the French company CMA-CGM (Porter, 2009).

Such evidence leads us to interpret the current transformations of Atlantic liner networks by referring to the wider recent study field of network analysis. The changes observed throughout the Atlantic depict an increasing concentration of the network upon some few main ports having many connections, while a larger proportion of ports have very low connectivity. This structural evolution clearly confirms the general properties of a scale-free network. We define a scale-free network as a network whose degree distribution follows a Power law as compared to a Gaussian distribution (Barabasi and Albert, 1999). One other important dimension of scale-free networks is their evolution through preferential attachment: new nodes are added to the graph through connecting to already centrally located nodes. Such framework seems relevant for the study of hub-and-spoke formation within maritime networks. The evolution of maritime networks generates "small worlds" defined as regional or specialized groups that we can define as specific clusters where ports observe a high dependency to one or to a group of other ports.

The remainders of this paper are as follows. Section 2 proposes a reflection about the lack and relevance of graph analysis in maritime and port studies. Section 3 introduces the data and methodology used for a multi-level analysis of the Atlantic liner network. Finally, conclusions are given in section 4 on the lessons learned for policy recommendation and further research.

\section{The network analysis of seaports}


Despite the network nature of transportation, new concepts that emerged from physics in the 1990s were not developed enough in this field. The following section recalls the main evidences and empirical results obtained by "classic network approaches" that lead to apply these new concepts to transport.

\subsection{Brief background on network analysis in transport geography}

Geographical research on networks for fifty years may be briefly summarized in three categories of approaches. The first is the morphological or topological approach developed by Garrison (1960) and Kansky (1963) applying mathematical graph theories to transport networks in order to study their fundamental properties through measuring indexes and verify their relation with regional development issues. A second approach is more functional, which is more specific to certain sectors, and is based upon economical measures (e.g. time and cost) rather than geographical distance (Martin, 1985). Finally, a third approach deals with cognitive space based on individual or group practices in terms of itineraries and transport modalities, complementing former studies by subjective factors.

The analysis of transport flows within a given network (first approach) uses a variety of tools that can be classified itself in three main categories (Charlier, 1981). One approach consists in applying graph theory to gravitational models. A second approach measures the efficiency of flows through the resolution of transport-related issues through specific applications derived from operations research and linear programming. Finally, a third approach is the descriptive statistical analysis using multivariate analysis of flows matrices. A common problem is that in practice, scholars rarely access detailed information on effective flows; therefore researchers base their measures on the physical layout of the transport network itself. At central place in transport geography is the estimation of nodal accessibility. The Koenig number for instance measures the number of shortest paths from one node (or vertex) to all other nodes within the graph. Beyond the simple counting of edges (or arcs), measures can take into account the different length units as proposed by Shimbel (Haggett, 1973).

More recent works in the field of analysis of scale free networks hovers around the idea of developing models to generate scale free networks (Barabasi and Albert, 1999), applying different statistical measures (Burda et al., 2001), and clustering these networks (Paivinen and Gronfors, 2005). The clustering of a graph corresponds to the search for 'small worlds', i.e. highly interdependent groups of nodes. Recent research in geography includes analysis on air 
transport networks (Amiel et al., 2005), commuter graphs (Rozenblat and Tissandier, 2007), and geographical networks in general (Rozenblat et al., 2008). Because describing in detail the content of such methodologies would reach beyond the scope of this paper, we propose a direct application to maritime transport. Before presenting the results based on the Atlantic, an overview of how relevant is network analysis for maritime transport is necessary.

\subsection{Applicability to and relevance for maritime networks}

\subsubsection{Changing economic context and paradigms}

Recent studies in economic geography show how reduced trade barriers (Clark et al., 2004), and shrinking transport costs in general (Glaeser and Kohlhase, 2004; Behrens et al., 2006) create a new context in which the relative, rather than inherent qualities of transport nodes - of which ports - become central issues (Limao and Venables, 2001). The successive levy of political, economical, and technological barriers in many parts of the world as a result of globalization and regionalization processes leads to "the ultimate system of maritime transportation [that] is a true freedom of the seas whereby every port node can theoretically be linked to every other port node" (Bird, 1984, p. 26). The global maritime network has become a reality on its own that does not entirely overlap trade patterns (Frémont, 2007a), although in the end, carriers tend to follow settlement patterns. Thus, changes in the economic organization of shipping lines and of the requirements imposed by shippers (e.g. transit times, connectivity, logistics reliability) are reflected in the new geographical organization of maritime networks: "the structure of liner shipping networks evolves over time [therefore] the position of ports as nodes in the network also changes over time (...) understanding these changes is crucial for analyzing the competitive position and growth prospects of container ports" (Langen de et al., 2002, p.1).

However, maritime networks did not receive as much attention as land-based transport networks in which ports are embedded. This is probably because maritime networks have increasingly been integrated to other transport networks: the "new paradigm" proposed by Robinson (2002). Therefore, a reflection on transport, logistics, supply, and logistics chains has superseded the classic modal separation. Shipping lines, terminal operators, but also of other players such as shippers and intermediaries (Ducruet and Van der Horst, 2009) integrate with each other so as to provide efficient and widespread services supporting and shaping 
globalisation. The limited cost of maritime transport compared to the land service has motivated scholars finding solutions for a better landward efficiency (Notteboom, 2004).

Therefore, transport geographers have concentrated their efforts on the study of port competition through hinterland accessibility, port regionalization, and port system evolution with a preference to landward relations (Rozenblat, 2004; Notteboom and Rodrigue, 2005). While this is perfectly understandable given the evolution of transport networks, the lack of interest for maritime networks alone remains paradoxical for one main reason: the biggest drivers of change are shipping lines. Port selection strategies of increasingly powerful carriers have profoundly modified the network structure of many port regions worldwide (Slack, and 1993; Hoffmann, 1998). Although an immense literature exists on port selection criteria by shipping lines and shippers (see $\mathrm{Ng}, 2009$ for a recent and thorough synthesis), it concentrates mostly on economic criteria. Conceptual advances about the evolving geography of maritime networks (Fleming and Hayuth, 1994; Rodrigue et al., 1997; Fleming, 2000; Baird, 2006) have found limited application in terms of network analysis and visualization.

Some geographers however have paved the way towards such analysis, notably when analyzing the strategies of ocean carriers through the spatial extension and expansion of their port networks, such as the study of Maersk by Frémont (2007b) and the regional networks of ocean carriers in Asia (Robinson, 1998; Comtois and Wang, 2003; Rimmer and Comtois, 2005; Ducruet et al., 2010). However, the relative position of seaports within the network is not systematically measured, nor is the network fully visualized as it is restrained to few main services (i.e. trunk lines), thus excluding local services (i.e. feeder links). Networks were visually simplified through measuring interregional flows in order to catch an overall spatial pattern, such as the global bipolar structure of the global maritime network (Joly, 1999) or the specific pattern of individual carriers (Frémont and Soppé, 2005) based on vessel capacities.

On the other hand, other approaches put more emphasis on the economic strategies of carriers such as alliance and integration (Bergantino and Veenstra, 2002; Bergantino and Veenstra, 2007; Veenstra and Parola, 2007) or on port performance and competition in the network (Veenstra et al., 2003; Wilmsmeier and Hoffmann, 2008). One common point of these works is to somewhat neglect the regional dimension of inter-port linkages because they do not assess the changing relation between network structure and firms' strategies. Finally, operations research about liner networks often lacks of a geographical focus by focusing dominantly on economic performance while modelling port selection mechanisms (Zeng and Yang, 2002; Song et al., 2005; Shintani et al., 2007), and the optimisation of liner shipping 
routes (Fagerholt, 2004). Practical constraints explain for a large part the limited analysis and visualization of large maritime networks.

\subsubsection{Constraints to a network analysis of maritime transport}

Apparently, there is no reason why maritime networks should not be analysed exactly like other transport networks (Joly, 1999) such as bus, road, rail, and river. Yet, their specificity is that the spatial design of maritime networks depends solely on carriers' circulations due to the absence of an infrastructure of track as in air transport (White and Senior, 1983). Unlike air networks, maritime networks are spatially constrained by coastal geography: vessels cannot cross continents unless a canal exists. For the rest, oceans allow a great freedom of circulation despite physical factors such as permanent or seasonal icing, depth requirements of bigger vessels technically (e.g. port entrance channels), and political barriers such as the former interdiction to establish direct calls between Taiwan and mainland Chinese ports. As a result, maritime networks form a vaguely defined distribution compared with land networks (Rodrigue et al., 2006), due to greater spatial complexity and volatility.

But the main reason explaining the lack of application of network theory to seaports is more to be found on the practical side of the problem: the rarity of detailed information on maritime circulation including nodes (ports), links (sea lanes), and flows (traffic). Some scholars adopted an intermediate solution using, for instance, data obtained from the French Meteorological Office reporting every six hours the position of about 4,000 vessels worldwide (Brocard et al., 1995), but this could not base a network analysis per se. Historians and geographers tended to represent circulation patterns in a very broad way based on qualitative sources (Westerdahl, 1996). The time needed for gathering and encoding data from various paper-based sources on vessel movements (Joly, 1999) as well as the cost of existing numeric information easily explain transport geographers' reluctance confronting such issue. In addition, a comprehensive visualization of shipping networks was difficult simply due to the fact that classical tools of cartography remained limited in representing complex and vast networks, before freeware such as TULIP and others became available to the public.

For such reasons, seaports are often compared regardless of their type of connection on the maritime side, although it can be hypothesized that the characteristics of seaborne connections are a fundamental element of port performance. Early studies of maritime forelands have shown the specialization of ports in terms of geographical reach in developed countries (see Bird, 1969). The lack of detailed, accessible data on maritime networks and 
related analytical tools often constrained international comparison to local attributes such as throughput volumes, physical equipments, terminal or crane productivity, and number of vessel calls (Langen de et al., 2007).

Some recent contributions however have explicitly addressed the usefulness of network analysis for a better understanding of the relative position of ports within a given network. This is the case of McCalla et al. (2005) when visualizing changes in network patterns of liner shipping within the Caribbean basin, and of Cisic et al. (2007) in their use of visualization software for measuring and representing the Mediterranean graph of liner shipping networks. Other examples on a world level include the work of Angeloudis et al. (2007) looking at the relation between port and maritime security with the structure of liner networks, Low et al. (2009) measuring the hub status of some Asian ports based on their connectivity within liner networks, and the study of Wang (2008) showing world maps of the port hierarchy based on their centrality in liner shipping networks. Nevertheless, it seems that classical cartography remains dominant in the field while it does not exploit the possibilities offered by specialized visualization software. The case of Atlantic liner shipping networks is proposed as an attempt to further exploit such possibilities.

\section{A case study of Atlantic liner networks}

Our research would like to complement such studies by further exploring the geographical dimension of liner networks within a given region. Three main directions are chosen: a) improve the quality of visualization of liner networks in order to better illustrate the relative position of seaports; b) verify whether the hub strategies have modified the structure of the network as a whole, and c) assess what are the geographical implications of such changes for the port hierarchy.

\subsection{Data source and methodology}

This paper proposes tackling these lacunae head on by providing an analysis of the geographical organization of maritime networks resulting from the daily circulation of sea-

going vessels. Because this study does not wish to describe in detail the pattern of every shipping line and the position of every port, it proposes aggregating the data in such way that the overall structure of the network becomes apparent and readable. Therefore, our definition of the maritime network is the combination of all shipping linkages between ports within a 
given period and area. Data was derived from Lloyd's MIU and includes all daily vessel movements in 1996 and 2006. The chosen period is particularly relevant for analyzing the spatial impact of hub strategies because new trends such as increased vessel size and route rationalization really started around 1995 (Cullinane and Khana, 2000). This diachronic approach reveals both structures and particular events of the systems dynamic. The resulting graphs of inter-port links can thus be analyzed using usual techniques of network measurement, and can be interpreted with systems properties. Choices implied by a necessary simplification of reality should be briefly introduced before going further.

Firstly, an analysis including all vessel movements overlaps different types of services and ports. Liner services vary in terms of geographical scope, weight (e.g. local, regional, and transcontinental) and function (e.g. direct call or line-bundling, interchange, and hub-andspoke), as seen in Figure 1. Each vessel draws a graph while circulating as it connects ports to each other through direct and intermediate calls.

\section{[Insert Figure 1 about here]}

In order to build a graph harmoniously, the continuum dynamic of vessels (i.e. via intermediate ports of calls) is changed to a juxtaposition of individual segments. In addition to the characteristics of liner services, the locational quality of ports is also very important when it comes to analyze the port hierarchy. For instance, upstream river ports such as Antwerp and Hamburg tend to handle much more containers per vessel call than coastal seaports such as Le Havre, partly to compensate for the diversion distance along the river. Maritime networks are only one component of the foreland-port-hinterland triptych (Vigarié, 1968); therefore ports' relative position in such networks addresses only partly their overall performance as transport nodes. While hinterland ports are de facto amputated from their inland centrality, pure transhipment hubs situated on islands or peninsulas are better represented because their activity is dominantly maritime-oriented. However in reality, very few ports are fully hubs or gateways; the two functions are more likely to coexist in every port while such distinction remains very theoretical. The analysis of direct inter-port links has the advantage harmonizing the diversity and complexity of service patterns.

Secondly, the data source itself has its advantages and its limits. It is based on effective circulations rather than the offer of services, and provides a very precise picture of the network since it covers about $98 \%$ of the world fleet of fully cellular container vessels, from 70 TEUs (e.g. barge, feeder) to 12,508 TEUs (i.e. Emma Maersk), allowing a complete 
overview. The main drawback is the impossibility distinguishing commercial port calls from other calls such as ship repair and bunkering. Therefore, the relationship between vessel traffic and port handling operations may not be straightforward, although this lack can be filled by a comparison with official port traffic statistics. Another inconvenient of the data for estimating port activity is the mismatch between full vessel capacity and the real amount of cargo loaded and unloaded at the terminals. Despite such limitations, this data provides an unchallenged source for the in-depth analysis of inter-port flows from a network perspective.

Finally, one very important choice - especially for geographers - influencing final results is the geographical extent of the study area. As remarked by Slack (1999), the spatial complexity of liner shipping makes it difficult delimitating with clarity the geographic limits of maritime regions such as the Atlantic. Indirect linkages such as Europe-Asia shipments via the Panama Canal may not be considered "Atlantic" while such vessels often call at Caribbean ports where interchange (mother vessel to mother vessel) or hub-and-spoke (mother vessel to feeder vessel) services coexist with Europe-US or Europe-Latin America lines. Identically, eastbound North Europe-Asia shipments have no option but to sail through the Atlantic from Le Havre to Gibraltar Straits to connect the Suez Canal and the Middle East. For such reasons, this paper proposes to delimit the Atlantic network based on the classic definition of the Atlantic Ocean but it extends it to North European countries of which Belgium, The Netherlands, and Western Germany where main European gateways are located. Based on Figure 1, several analyses are made possible:

- Graph of direct links: this analysis considers inter-port connections without including intermediary calls, i.e. based on previous and next ports of call. It highlights the position of ports based on the simple topology of the network.

- Complete graph: this includes intermediary calls so as to take into account the complexity of vessel movements. For instance, a vessel calling successively at ports A, $\mathrm{B}$, and $\mathrm{C}$ results in three links $(\mathrm{AB}, \mathrm{BC}$, and $\mathrm{AC})$ as opposed to two links only in the previous analysis (see Figure 1).

- Weighted links: from the complete graph, the analysis of regional dynamics through clustering is applied including the total vessel capacity circulated measured in twentyfoot equivalent units (TEUs).

\subsection{The Atlantic liner network}




\subsubsection{Network structure and port hierarchy}

The first step of our analysis is to visualize the graph of direct inter-port links for 1996 and 2006 (Figure 2). The relative position of ports is highlighted by a hierarchy of size through their maritime degree ${ }^{3}$ and by a greyscale of betweenness centrality ${ }^{4}$. The relative position of ports in the graph is based on a layout that puts the most central ports in the centre and the least central to the periphery.

\section{[Insert Figure 2 about here]}

We see that at both years, Rotterdam is the most central port in the network. This underlines that the overall structure of the network has remained rather stable over time. However, some changes are perceptible. The number of highly central ports seems to have dropped during the period. Some ports such as Le Havre and Antwerp have maintained, but others such as Bilbao and Lisbon (Iberian Peninsula), Manzanillo and Houston (Americas), have seen their position greatly reduced. Conversely, some ports have increased their position: the best example is Kingston, precisely the port that is described in the literature as the fast growing hub of the Caribbean. Therefore, the position of Kingston has expanded not only in its own region but also in the Atlantic network as a whole, which confirms that hub strategies of carriers have influenced the structure of the network beyond local reorganization. Although visualization may help understanding those changes, it has to be complemented by other analyses.

The second step is to determine to which type of network the Atlantic graph belongs. In Figure 3, we compare the number of connections or "degree" with the cumulated distribution of ports in logarithm (Watts, 1999; Newman, 2000; Newman et al., 2006). Lessons from the figure are twofold. First, there is no doubt that the observed distribution forms a power-law distribution because of slopes remaining over 1. It confirms that some ports concentrate many more connections than others. Thus, the Atlantic network is a scale-free network that is

\footnotetext{
${ }^{3}$ Number of ports (vertices) directly connected to a given port through inbound and outbound direct maritime connections (edges). This paper does not measure a deeper degree (e.g. level 2, 3, or more) but this is used extensively in sociology and communication science for analyzing diffusion processes (Monge and Contractor, 2003). In the case of maritime transport, extending the measure of degree would highlight possible transfer steps in the vicinity of ports.

${ }^{4}$ Sum of all possible shortest paths of the graph passing through a given port. This measure can reflect a "potential maritime accessibility" and can be interpreted as a level of intermediacy - or in-betweenness condensing multiple insertions of ports within the networks of ocean carriers and their ability connecting various scales from the local to the global (Fleming and Hayuth, 1994).
} 
organized by a few dominant nodes and a majority of secondary nodes. Second, this characteristic has remained very stable over time. Yet one may notice a slight decrease between 1996 and 2006, as notified by the slope of the line (from -1.18 to -1.07). It means that the hierarchy is decreasing, showing a diffusion process to different poles or hubs. Thus we can assume that while the Atlantic network remains polarized upon a few dominant hubs, the combination of trade growth, port competition, and shipping line reorganization have generated a larger number of dominant ports. Additional evidence is brought by applying the Gini coefficient to the distribution of traffic within the graph. Traffic concentration on links (edges) and among ports (vertices) has decreased from 0.867 to 0.863 and from 0.863 to 0.860 respectively, what confirms a small decrease in hierarchization, parallel to a greater complexity of the network. Lastly, observed connectivity versus optimal connectivity ${ }^{5}$ has increased from 0.019 to 0.029 because many more ports are interconnected in 2006 compared with 1996, making the network denser. The rest of the analysis will verify to what extent such phenomena have also deeper geographical implications, in terms of regional organization of the graph.

[Insert Figure 3 about here]

\subsubsection{Regional polarizations: the dominant flow graph}

In order to visualize the geographic impact of the aforementioned evolutions, a useful analytical tool is to filter the database and retain only the dominant traffic connection of each port with another port (Nystuen and Dacey, 1961). This measure has been used elsewhere in the case of ports (Ducruet, 2008) under the concept of "hub dependence", as a level of vulnerability when calculating the share of the dominant flow in total port traffic. This method allows revealing the network's fundamental structure (Figure 4).

Ports with a wider set of dependent satellites appear as the pivots of the system, with Rotterdam as the central player, dominating its European tributary area at both years. Over time the position of some other European ports has expanded, notably Hamburg, Algeciras, Antwerp, Zeebrugge, and Lisbon. This has important implications for the port hierarchy; for instance it seems that Algeciras has superseded Abidjan as Africa's main hub, while the

\footnotetext{
${ }^{5}$ We measure the observed connectivity by dividing the number of edges by the number of ports, and compare it with the optimal connectivity (i.e. assuming that all ports should be connected to each other). The Atlantic network is based on 307 ports (1,821 links) in 1996 and 351 ports (3,609 links) in 2006.
} 
strong position of Houston in 1996 has lowered to the advantage of Kingston in 2006. The stable position of New York is complemented by the increase of Miami and Port Everglades, as noticed in the recent literature on the North American Eastern seaboard. Outside Europe, gateway ports tend to see trunk lines shifting to emerging hub ports. Yet this trend is not true everywhere: Santos, Brazil's main port and gateway to Brazil's giant metropolis Sao Paulo, has kept - and even has increased - its position. A closer look at Europe reveals important shifts at the expense of some gateways: Dublin, Reykjavik, Bilbao, and Bristol (i.e. the true "Atlantic" ports) are not anymore main pivots in 2006, probably due to the reorientation and increased concentration of shipping lines towards North European range ports (Le Havre to Hamburg). This also applies to Liverpool, which was an important pole within a UK-Canada sub-region in 1996.

Overall, we observe a strong geographic logic in the results. Main pivots tend to polarize their belonged regional area as an effect of proximity. Further research may go deeper into the analysis of inter-port polarization, perhaps by refining the level of analysis from four large regions to smaller subsets of spatially coherent port ranges (e.g. West Africa, US Gulf coast, etc.). This analysis of dominant flows paves the way for verification about whether the Atlantic network has become more polarized or more integrated.

[Insert Figure 4 about here]

\subsubsection{Clusters of ports in the Atlantic}

The clustering methodology is now applied in order to detect possible small worlds or strongly interconnected components. In the case of ports, such clusters may correspond to regional and/or functional proximities created by the circulation patterns of vessels. The evolution of such proximities shall provide meaningful evidence about changes in the network structure. We have opted for "bisecting K-means", the most celebrated and widely used clustering technique according to Savaresi and Boley (2004), who classify this technique among iterative centroid-based divisive algorithms. In other words, it is used for revealing in a systematic way possible small worlds within a given graph based on geometrical and topological attributes. The number of small worlds and the number of iterations necessitated for revealing them provide strong evidence about the overall organization of the network. 
Applying the clustering methodology at both years and following identical criteria6 led to distinct results in 1996 and in 2006 (Figures 5 and 6). Each "level" represents one bisecting operation that is repeated until no more relevant clusters can be found. In terms of overall structure, the main result is a shift towards greater complexity. Although the dominance of North European and Latin American ports remains rather stable, the clusters seem characterized by an increasing spatial complexity. As previously noticed, the combination of trade growth, regional integration processes, and carriers' port choices have made the network denser with a mix of hub-and-spoke and direct call services (see Guy, 2003). Regional proximities and geographic variety of inter-port linkages may have been exacerbated or blurred depending on the level of integration of local cycles in such services. We select some examples of noticeable permanencies and shifts as a means illustrating such trends.

In 1996, several clusters exhibit a strong influence of historical and preferential trade relations. For instance, clusters $1 \mathrm{a}$ and $1 \mathrm{c}$ reflect the respective foreland specialization of Rouen (and other French ports) on West Africa and of Iberian Peninsula ports (Lisbon, Bilbao) on Brazil (e.g. Belem). Indeed, Rouen is well connected to many African ports through regular services from Delmas and CMA-CGM, while Algeciras (Spain) was in the 1990s a pioneer hub port of the Maghreb. Such specific ties clearly highlight the important overlap of shipping networks and trade networks. This is also the case for cluster $4 \mathrm{~b}$ with German ports (Hamburg and Bremen) grouped together with several main Brazilian ports, which underlines the importance of Germany in Brazil's international trade, dating back to the 1930s. Despite the importance of North Atlantic shipping, most of North America's main ports have stronger linkages with Latin America than with Europe. Philadelphia's inclusion with a number of Central and South American ports (3e) is probably influenced by the key role of its Tioga Terminal for fruit trade. Baltimore has a long tradition of non-containerized cargo links with South America (4a) that has been lately pursued through the Tango service with Brazil for containers. Other clusters with North American ports confirm this trend, with New York, Miami polarized by Kingston due to the hub effect (3f), Houston and other Gulf ports linked with Mexico (3b), New Orleans and Central America (3h), Florida ports and the Antilles (3g). Other clusters are characterized by very local cycles, such as the Irish cluster (3c), the UK-Iceland cluster (2b), and the Canary cluster (3d), although the two latter have a peculiar structure as they connect virtually all Atlantic regions despite their smaller size.

\footnotetext{
${ }^{6}$ The methodology is applied on all direct and indirect weighted edges (traffic in TEUs) as the clustering metric.
} 
Finally, the emergence of the North European range (4c) provides a good example of strong interdependency through exploiting spatial proximity: Europe's largest gateways (i.e. Le Havre, Southampton, Antwerp, Rotterdam, and Bremerhaven) constitute the core of the entire Atlantic system.

In 2006, the aforementioned influence of traditional trading links is still visible in some clusters. For instance, we see more clearly the former colonial ties of Lisbon through the inclusion of several Brazilian (e.g. Santos, Salvador, Manaus) and African ports (e.g. Angola) in cluster 2b. Another example is cluster $2 \mathrm{~g}$ with Bilbao and Santander (Spain) having strong links with a series of Latin American ports (Antilles). Some small clusters remain predominantly local in scope, such as French ports (1b), UK-Iceland (1c), West Africa (2f), Northern Brazil (2h), two Irish clusters (3a and $3 \mathrm{~d}$ ), and another UK cluster centred upon Tilbury (3b). Contrastingly, cluster 2 a stands out by its great geographic variety with Le Havre (Paris), Felixstowe (London), Houston, Miami and several other main ports. The inclusion of New York as well suggests the interconnection between several global cities through such links. Another observation is the stronger separation between Latin America and Europe on Level 3 compared with 1996. Antwerp (3c), Rotterdam, and Hamburg (3e) primarily polarize European ports within their respective clusters. On the other side of the Atlantic, ports of Florida (Jacksonville, Port Everglades) and the US Gulf (New Orleans) polarize Central American (3f, 3j) and Brazilian ports (3h) respectively. Puerto Cabello (Venezuela) and Puerto Cortes (Honduras) seem to centralize nearby ports (3g, 3i) while transhipment hubs such as Kingston, Port of Spain, and Rio Haina (and also Algeciras) do not appear as the most central ports anymore. The hypothesis that the rationalization of the network by ocean carriers would blur the spatial logics of trade patterns due to the hub effect is not fully verified in the results. Hub-and-spoke services that are based on short-term economic factors of shipping lines do not contradict longer-term evolutions based on historical ties and regional integration. Perhaps, such hub ports reinforce rather than put in question regionalization processes through their consolidating role.

[Insert Figures 5 and 6 about here]

\section{Conclusion}


Based on graph theory and network analysis, the study of liner circulations within the Atlantic area is fruitful in several aspects. First, it confirms that maritime networks can be analyzed like other transport networks. The accuracy of vessel movements makes it possible to obtain a precise picture of a given maritime network, notwithstanding necessary data computing in order to sharpen the results when it comes to the analysis of inter-regional linkages. The relative position of seaports is made evident and their performance as nodes as well: this is a good complement to traditional measures of individual throughput. Second, the scale-free dimension of liner networks that stems from the spatial behaviour of carriers has been revealed, showing that over time, this dimension slightly decreased, due to the emergence of new hubs besides traditional gateways, in a context of growing regional integration. An application of recent methodologies specific to network analysis allowed identifying regional structures or small worlds within the Atlantic.

Although our analysis shows some permanencies, we see that traditional circulation patterns are less visible in 2006 compared with 1996. We interpret these changes by a combined effect of regional integration (i.e. multiplication of links, growing trade) and port competition (i.e. emergence of more many larger ports at the top of the hierarchy). Overall, graph theory and network analysis bring new insights to the field of port and maritime geography. However, given the empirical lacks in existing literature, this paper has mostly concentrated on methodological aspects. This leads us to discuss more the notion of maritime networks in a globalizing world; the geographical dimension of maritime networks is at stake in port studies, given the increasing power of shipping lines designing their services around the globe. The optimal maritime network described by Bird (1984) may have become a reality where regional and historical proximities confront the trend of contemporary ubiquity facilitated by technological improvements and the search for optimal economic efficiency. However, results also show the relative permanency of some regional spatial structures underlying maritime linkages.

Further research may concentrate on possible improvements. First, more comparison is needed among connected ports in terms of performance indicators. This paper has retained the most usual measures (degree and centrality), while existing tools provide many more. This would constitute a field of research per se, i.e. to compare the traditional throughput measure with more sophisticated network attributes of seaports. Second, the same analytical tools may be applied to other metrics than total vessel capacity, such as traffic frequency (e.g. weekly, monthly number of calls or vessels), in order to take into account the time proximities between ports. Third, further application of social network analysis techniques to maritime 
transport would gain from better analyzing network dynamics, notably in terms of preferential attachment among ports over time showing the built of the hierarchies between ports at different levels of geographical scales. Fourth, such analysis may benefit from refining the analysis by carrier, vessel size, or service type. The problems related with the complexity of liner networks were overcome in this paper by the aggregation of all carriers, vessels, and services, although in reality each of these aspects have specific implications, notably through the distinction between intra-regional and inter-regional connections.

\section{Acknowledgements}

This research has benefited financial support from Marie Curie Fellowship (EIF-FP6) and Reintegration Grant (ERG). Authors would like to thank Prof. Jean-Paul Rodrigue (Hofstra University) and Prof. Theo Notteboom (ITMMA) for their useful comments on an earlier version of this paper.

\section{References}

Amiel, M., Mélançon, G. and Rozenblat, C., 2005. Multi-level networks: international flows of airline passengers. Mappemonde 79(3),

http://mappemonde.mgm.fr/num7/articles/art05302.html

Angeloudis, P., Bichou, K. and Bell, M.G.H., 2007. Security and reliability of the liner container-shipping network: analysis of robustness using a complex network framework. In: Bichou, K., Bell, M.G.H. and Evans, A. (Eds), Risk Management in Port Operations, Logistics and Supply Chain Security, London: Informa, pp. 95-106.

Baird, A.J., 2006. Optimising the container transhipment hub location in northern Europe. Journal of Transport Geography 14(3), 195-214.

Barabási, A.L. and Albert, R., 1999. Emergence of scaling in random networks. Science 286(5439), 509-512.

Behrens, K., Gaigné, C., Ottaviano, G.I.P. and Thisse, J.P., 2006. Is remoteness a locational disadvantage? Journal of Economic Geography 6(3), 347-368.

Bergantino, A.S. and Veenstra, A.W., 2002. Interconnection and co-ordination: an application of network theory to liner shipping. International Journal of Maritime Economics 4(3), 231248.

Bergantino, A.S. and Veenstra, A.W., 2007. Complexity in liner shipping networks. Paper presented at the International Association of Maritime Economists Conference, Athens, Greece, July 4-6.

Bird, J., 1969. Traffic flows to and from British seaports. Geography 54, 284-301.

Bird, J., 1984. Seaport development: some questions of scale. In: Hoyle, B.S., Hilling, D. (Eds), Seaport Systems and Spatial Change, Chichester: Wiley, pp. 21-41. 
Brocard, M., Joly, O. and Steck, B., 1995. Les réseaux de circulation maritime. Mappemonde 1, 23-28.

Burda, Z., Correia, J.D. and Krzywicki, A., 2001. Statistical ensemble of scale-free random graphs. Physical Review E 64, 046118.

Charlier, J. (1981) Contribution méthodologique a l'étude des arrière-pays portuaires, Louvain: Université Catholique de Louvain.

Cisic, D., Komadina, P. and Hlaca, B., 2007. Network analysis applied to Mediterranean liner transport system. Paper presented at the International Association of Maritime Economists Conference, Athens, Greece, July 4-6.

Clark, X., Dollar, D. and Micco, A., 2004. Port efficiency, maritime transport costs, and bilateral trade. Journal of Development Economics 75(2), 417-450.

Comtois, C., Wang, J.J. (2003) Géopolitique et transport: Nouvelles perspectives stratégiques dans le détroit de Taïwan, Etudes Stratégiques 34 (2), 213-227.

Cullinane, K. and Khana, M., 2000. Economies of scale in large containerships: optimal size and geographical implications. Journal of Transport Geography 8, 181-195.

Ducruet, C., 2008. Hub dependence in constrained economies: the case of North Korea. Maritime Policy and Management 35(4), 374-388.

Ducruet, C. and Horst van der, M., 2009. Transport integration at European ports: measuring the role and position of intermediaries. European Journal of Transport Infrastructure Research 9(2), 121-142.

Ducruet, C., Lee, S.W., Ng, K.Y.A. (2010) Centrality and vulnerability in liner shipping networks: revisiting the Northeast Asian port hierarchy, Maritime Policy and Management 37 (1), 17-36.

Fagerholt, K., 2004. Designing optimal routes in a liner shipping problem. Maritime Policy and Management 31(4), 259-268.

Fleming, D.K. and Hayuth, Y., 1994. Spatial characteristics of transportation hubs: centrality and intermediacy. Journal of Transport Geography 2(1), 3-18.

Fleming, D.K., 2000. A geographical perspective of the transhipment function. International Journal of Maritime Economics 2(3), 163-176.

Frémont, A., 2007a. Le Monde en Boîtes: Conteneurisation et Mondialisation. Arcueil: INRETS.

Frémont, A., 2007b. Global maritime networks: the case of Maersk. Journal of Transport Geography 15(6), 431-442.

Frémont, A. and Soppé, M., 2005. Transport maritime conteneurisé et mondialisation. Annales de Géographie 642, 187-200.

Garrison, W.L., 1960. Connectivity of the interstate railway system. Papers in Regional Science 6(1), 121-137.

Gilman, S., 1999. Sector competition and hub port potential in Atlantic container trades. Paper presented at the International Association of Maritime Economists Conference, Halifax, Canada, September 13-14.

Glaeser, E.L. and Kohlhase, J.E., 2004. Cities, regions and the decline of transport costs. Papers in Regional Science 83, 197-228. 
Guy, E., 2003. Shipping line networks and the integration of South America trades. Maritime Policy and Management 30(3), 231-242.

Haggett, P., 1973. L'analyse Spatiale en Géographie Humaine. Paris: Armand Colin.

Helmick, J.S., 1994. Concentration and Connectivity in the North Atlantic Liner Port Network, 1970-1990. Miami: University of Miami.

Hoffmann, J., 1998. Concentration in Liner Shipping: Its Causes and Impacts for Ports and Shipping Services in Developing Regions. Santiago: UN \& ECLAC.

Joly, O., 1999. La Structuration des Réseaux de Circulation Maritime. Unpublished PhD dissertation in Territorial Planning, Le Havre: Le Havre University.

Kansky, K.J., 1963. Structure of Transportation Networks: Relationship between Network Geometry and Regional Characteristics. Chicago: University of Chicago.

Langen de, P.W., Nijdam, M.H. and Van der Horst, M.R., 2007. New indicators to measure port performance. Journal of Maritime Research 4(1): 23-36.

Langen de, P.W., Lugt van der, L.M. and Eenhuizen, J.H.A., 2002. A stylised container port hierarchy: a theoretical and empirical exploration. Paper presented at the International Association of Maritime Economists Conference, Panama, November 13-15.

Limao, N. and Venables, A.J., 2001. Infrastructure, geographical disadvantage, transport costs, and trade. The World Bank Economic Review 15(3), 451-479.

Low, J.M.W., Lam, S.W. and Tang, L.C., 2009. Assessment of hub status among Asian ports from a network perspective. Transportation Research Part A: Policy and Practice 43, 593606.

Marcadon, J., 1999. Containerisation in the ports of Northern and Western Europe. Geojournal 48(1), 15-20.

Martin, J.P., 1985. L'analyse des réseaux en géographie. Groupe Réseaux 3, 229-249.

McCalla, R., 1999. From St. John's to Miami: containerisation at Eastern seaboard ports. Geojournal 48(1): 21-28.

McCalla, R., 2008. Container transhipment at Kingston, Jamaica. Journal of Transport Geography 16(3), 182-190.

McCalla, R., Slack, B. and Comtois, C., 2005. The Caribbean basin: adjusting to global trends in containerization. Maritime Policy and Management 32(3), 245-261.

Monge, P.R. and Contractor, N.S., 2003. Theories of Communication Networks. New York: Oxford University Press.

Newman, M.E.J., 2000. Models of the small world. Journal Statistical Physics 101, 819- 841.

Newman, M.E.J., Watts, D., Barabasi, A.L. 2006. The Structure and Dynamics of Networks. Princeton NJ: Princeton University Press.

Ng, K.Y.A., 2009. Port Competition: The Case of North Europe. Vdm Verlag Dr. Muller.

Notteboom, T.E., 2004. Container shipping and ports: an overview. Review of Network Economics 3(2), 86-106.

Notteboom, T.E., 2006. Traffic inequality in seaport systems revisited. Journal of Transport Geography 14(2), 95-108. 
Notteboom, T.E. and Rodrigue, J.P., 2005. Port regionalization: towards a new phase in port development. Maritime Policy and Management 32(3), 297-313.

Nystuen, J.D., Dacey, M.F. (1961) A graph theory interpretation of nodal regions, Papers in Regional Science 7 (1), 29-42.

Paivinen, N.S. and Gronfors, T.K., 2005. Modifying the scale-free clustering method. CIMCA '05: Proceedings of the International Conference on Computational Intelligence for Modelling, Control and Automation and International Conference on Intelligent Agents, Web Technologies and Internet Commerce Vol-2 (CIMCA-IAWTIC'06), IEEE Computer Society, 477-483.

Parola, F., Veenstra, A.W. (2007) The spatial coverage of shipping lines and container terminal operators, Journal of Transport Geography 16 (4), 292-299.

Porter, J., 2009. Suez Canal hit as CMA CGM considers bypass plans. Lloyd's List, January 28.

Rimmer, P.J., Comtois, C. (2005) China's extra and intra-Asian liner shipping connections, 1990-2000, Journal of International Logistics and Trade 3, 75-97.

Robinson, R., 1998. Asian hub/feeder nets: the dynamics of restructuring. Maritime Policy and Management 25(1), 21-40.

Robinson, R. (2002) Ports as elements in value-driven chain systems: the new paradigm, Maritime Policy and Management 29 (3), 241-255.

Rodrigue, J.P., Comtois, C. and Slack, B., 1997. Transportation and spatial cycles: evidence from maritime systems. Journal of Transport Geography 5(2), 87-98.

Rodrigue, J.P., Comtois, C. and Slack, B., 2006, The Geography of Transport Systems. New York: Routledge.

Rodrigue, J.P. and Guan, C., 2009. Port hinterland divergence along the North American Eastern seaboard. In: Notteboom, T.E., Langen de, P.W., Ducruet, C. (Eds.) Ports in Proximity. Essays on Competition and Coordination among Adjacent Seaports, Aldershot: Ashgate, 131-150.

Rowlinson M., 1999. North Atlantic Seaway: a study of competitive and organisational change in the container liner trades. Paper presented at the International Association of Maritime Economists Conference, Halifax, Canada, September 13-14.

Rozenblat, C. (Ed), 2004. Comparer les Villes Portuaires en Europe. Le Havre: Institut de Recherche en Stratégie Industrielle et Territoriale (IRSIT).

Rozenblat, C., Bourqui, R., Mélançon, G. and Auber, D., 2008. Community identification in geographical networks: a comparative survey. International Sunbelt Social Network Conference, January 22-27, St. Pete Beach, Florida.

Rozenblat, C. and Tissandier, P., 2007. Commuter graphs and cities' polycentric cohesion. Proceedings of the $15^{\text {th }}$ European Colloquium on Theoretical and Quantitative Geography (ECTQG), Montreux, Switzerland, September 7-11, pp. 345-355.

Savaresi, S.M. and Boley, D.L., 2004. A comparative analysis on the bisecting K-means and the PDDP clustering algorithms. Intelligent Data Analysis 8(4), 345-362.

Shintani, K., Imai, A. and Papadimitriou, S., 2007. The container shipping network design problem with empty container repositioning. Transportation Research Part E: Logistics and Transportation Review 43(1), 39-59. 
Slack, B., 1993. Pawns in the game: ports in a global transportation system. Growth and Change 24(4), 579-588.

Slack, B. (1999) Across the pond: container shipping on the North Atlantic in the era of globalisation, Geojournal 48 (1), 9-14.

Song, D., Zhang, J., Carter, J., Field, T., Marshall, J., Polak, J., Schumacher, K., Sinha-Ray, P. and Woods, J., 2005. On cost efficiency of the global container shipping network. Maritime Policy and Management 32(1), 15-30.

Starr, J.T., 1994. The mid-Atlantic load centre: Baltimore or Hampton Roads? Maritime Policy and Management 21(3), 219-227.

Veenstra, A.W., Mulder, H.M. and Sels, R.A., 2005. Analysing container flows in the Caribbean. Journal of Transport Geography 13(4), 295-305.

Vigarié, A., 1968. Géographie de la Circulation. Paris: Genin.

Wang, C.J., 2008. Spatial organization of world maritime container transportation networks. Geographical Research 27(3), 636-648 (in Chinese).

Watts, D.J., 1999. Small Worlds. Princeton NJ: Princeton University Press.

Watts, D.J., Strogatz, S.H. (1998) Collective dynamics of 'small-world' networks, Nature 393 (6684), 409-410.

Weigend, G.G., 1958. Some elements in the study of port geography. Geographical Review 48, 185-200.

Westerdahl, C., 1996. Traditional zones of transport geography in relation to vessel types. http://www.abc.se/ pa/publ/transport.htm (Accessed January 2009).

White H.P. and Senior M.L., 1983. Transport Geography. Hong Kong: Longman House Ltd.

Wilmsmeier, G. and Hoffmann, J., 2008. Liner shipping connectivity and port infrastructure as determinants of freight rates in the Caribbean. Maritime Economics and Logistics 10(1-2), 130-151.

Zeng, Z. and Yang, Z., 2002. Dynamic programming of port position and scale in the hierarchized container ports network. Maritime Policy and Management 29(2), 163-177. 
Figure 1: From vessel movements to graph analysis and port hierarchy

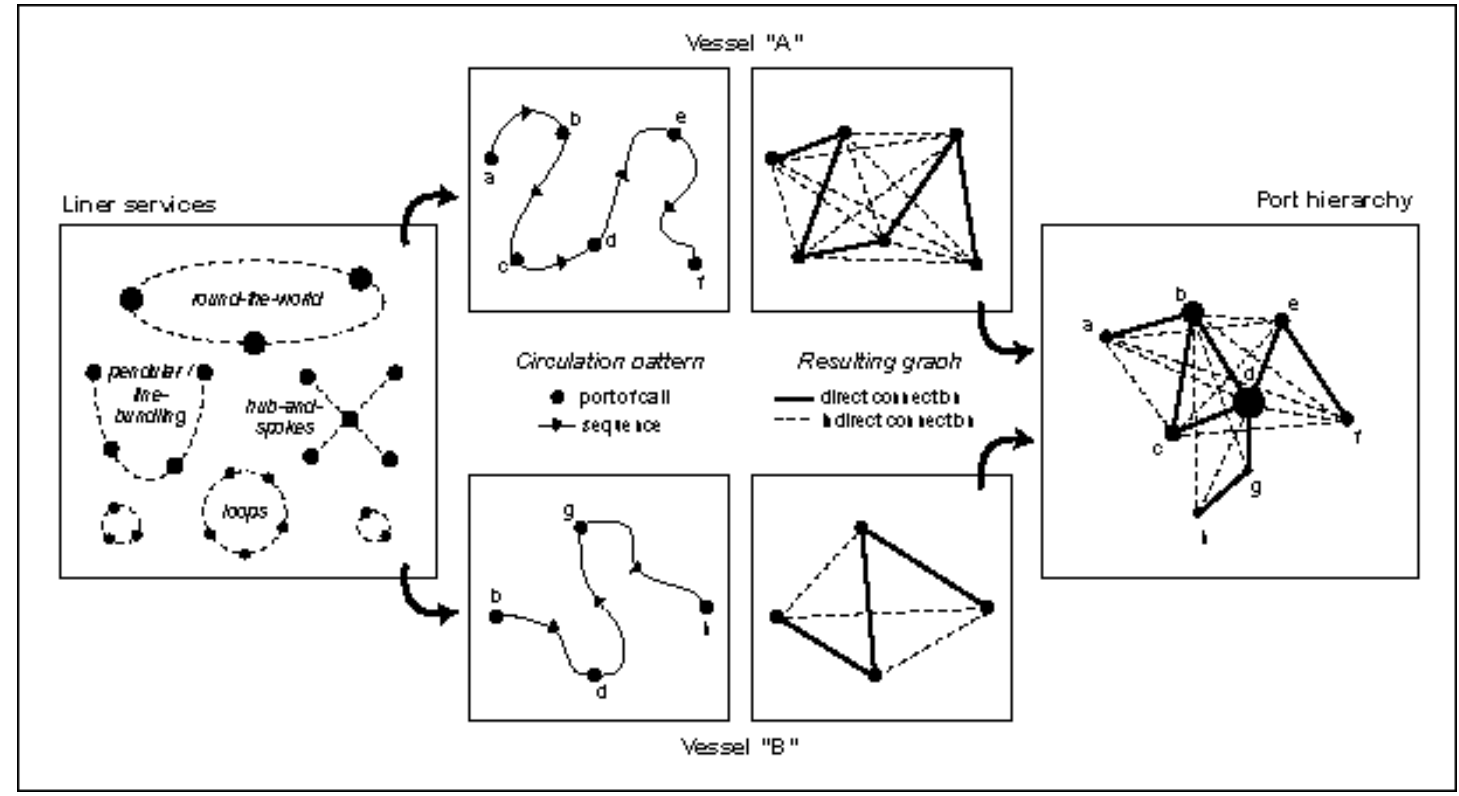

Example 1: Direct call service (North Atlantic)

Example 2: Hub-and-spoke service (Caribbean) Vessel flag ATG / Built 2006 / Capacity 2,490 TEUs Vessel flag ATG / Built 1997 / Capacity 980 TEUs

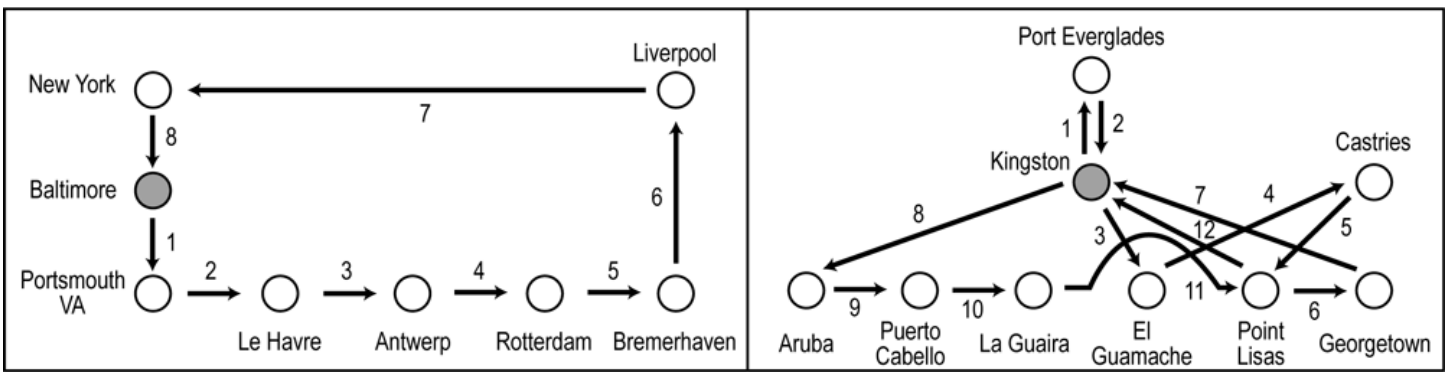

Source: realized by authors 
Figure 2: Graph visualization of the Atlantic liner shipping network, 1996-2006

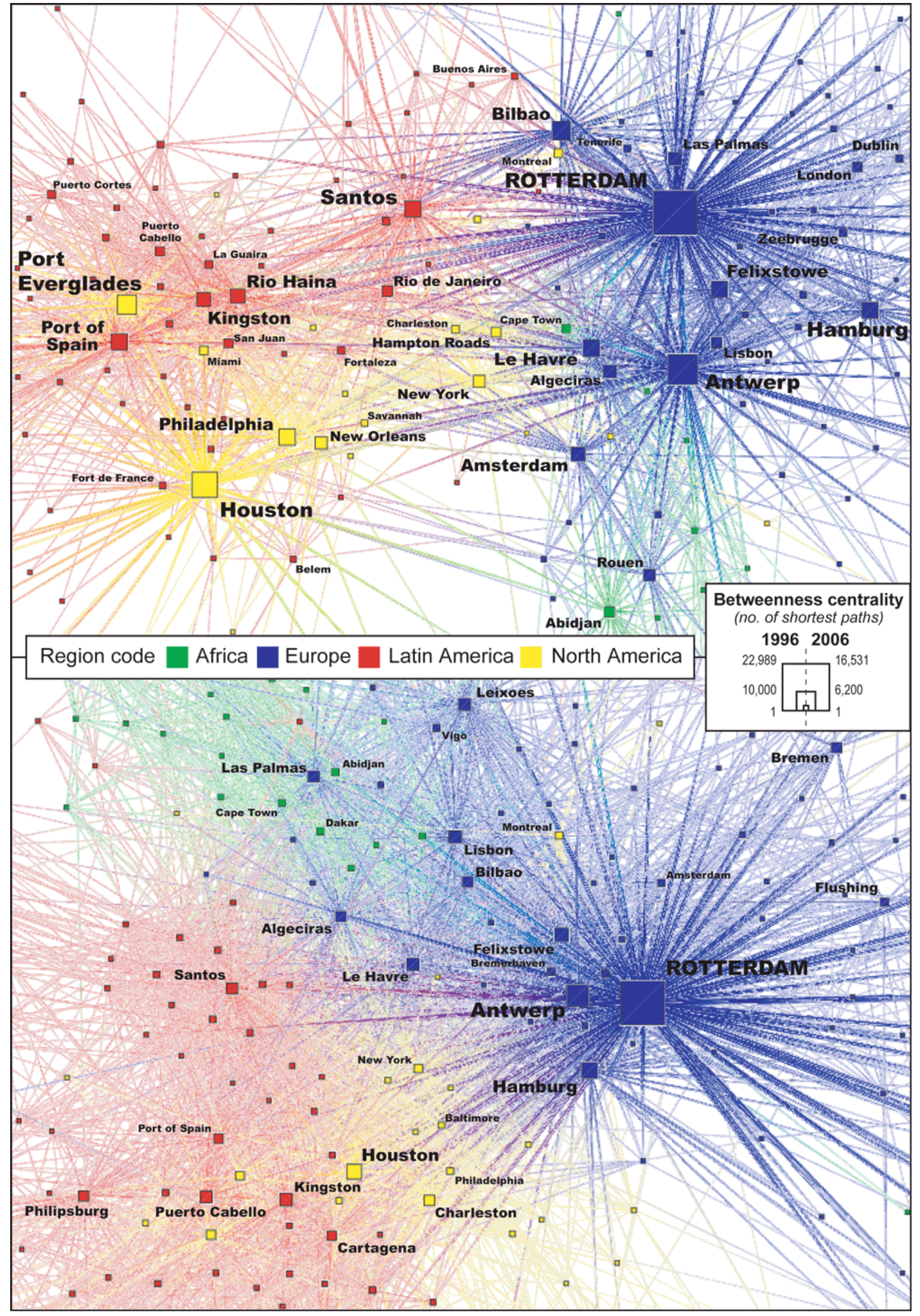

Source: realized by authors based on LMIU data and TULIP software 
Figure 3: Scale-free structure of the Atlantic liner shipping network, 1996-2006

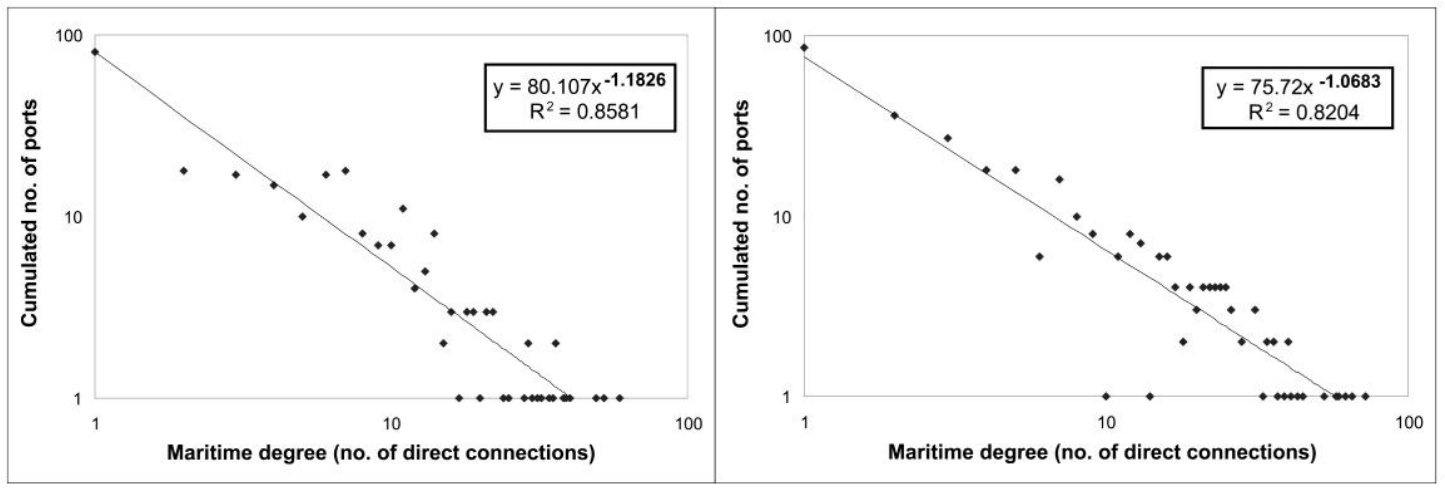

Source: realized by authors based on LMIU data

Figure 4: Graph visualization of dominant inter-port links, 1996-2006

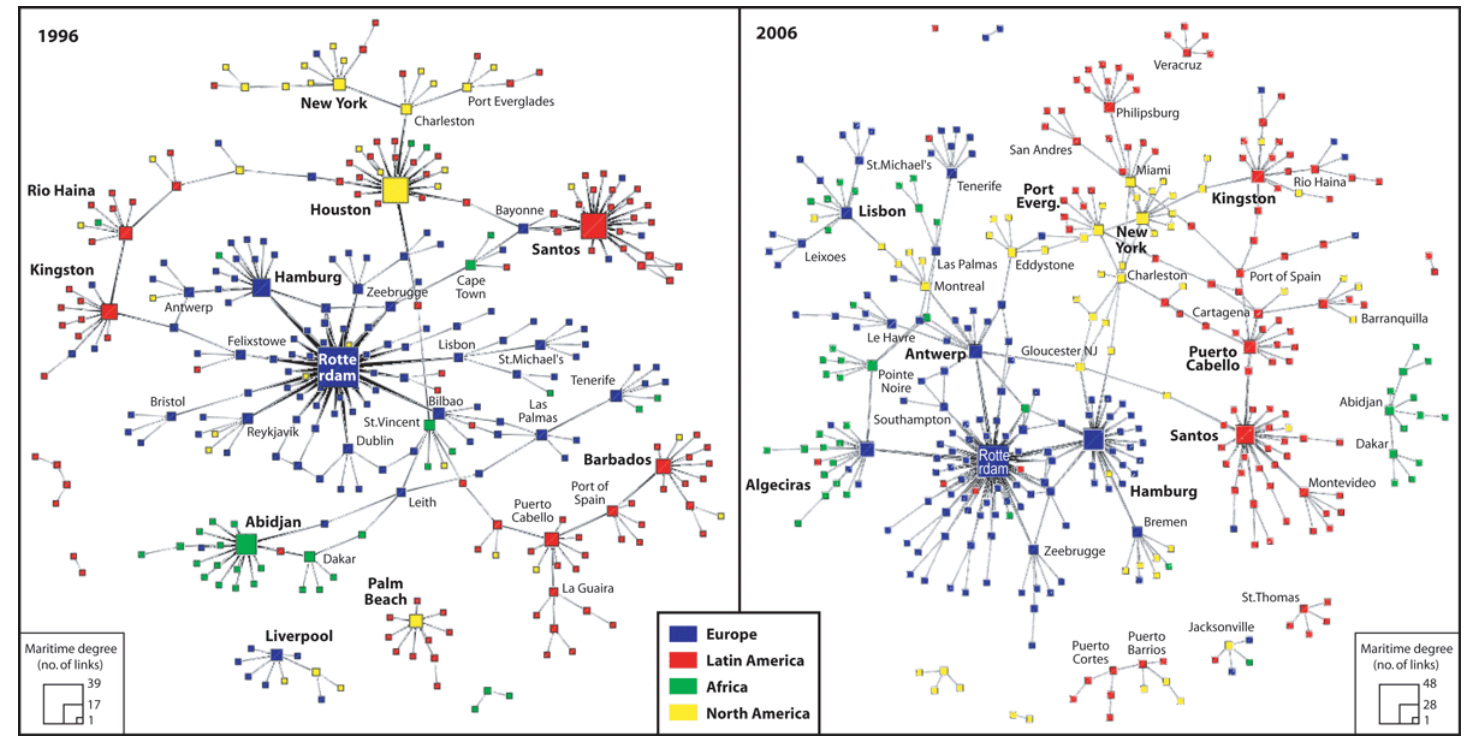

Source: realized by authors based on LMIU data and TULIP software 
Figure 5: Clusters of ports within the Atlantic network, 1996

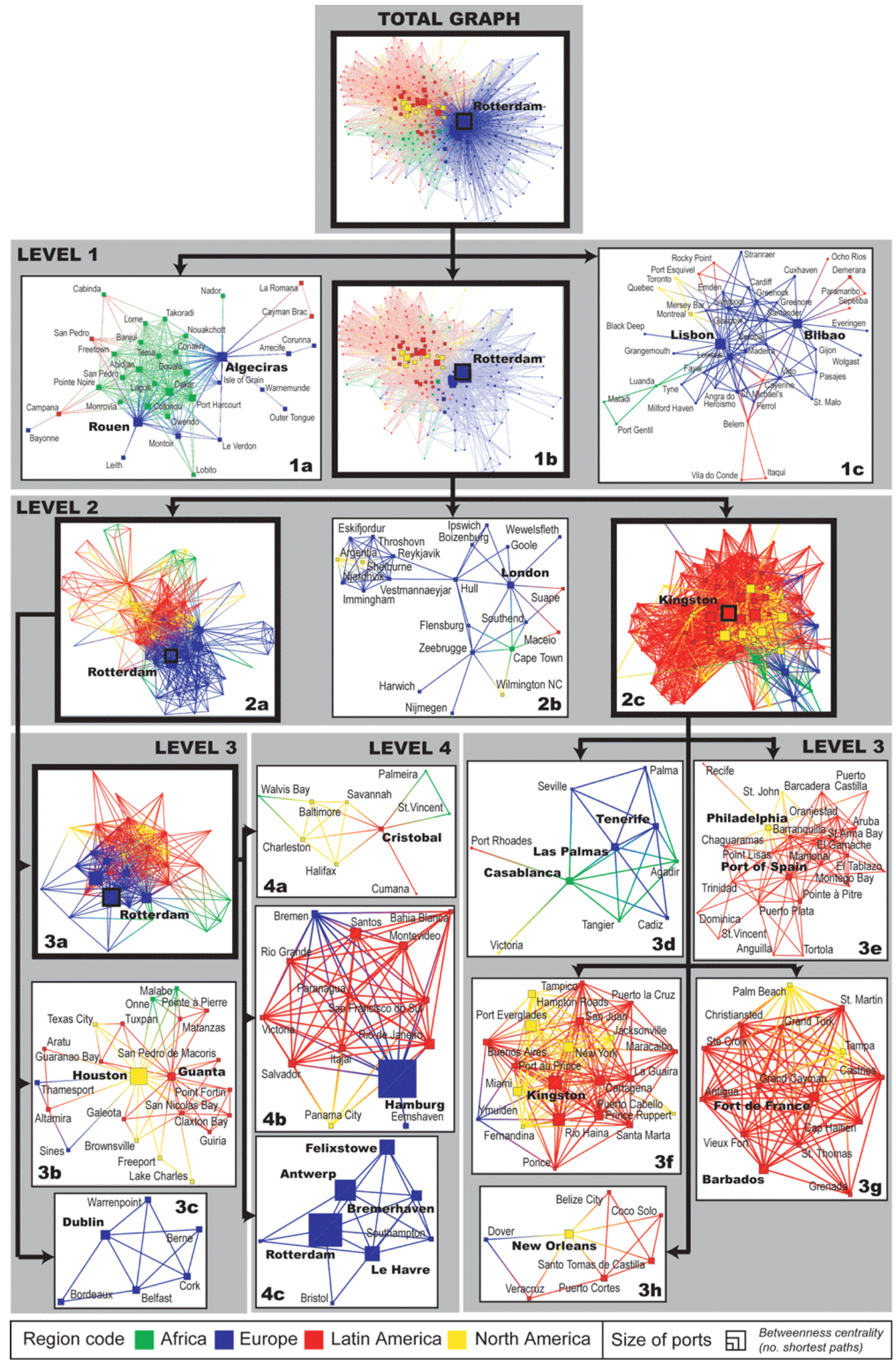

Source: realized by authors based on LMIU data and TULIP software 
Figure 6: Clusters of ports within the Atlantic network, 2006

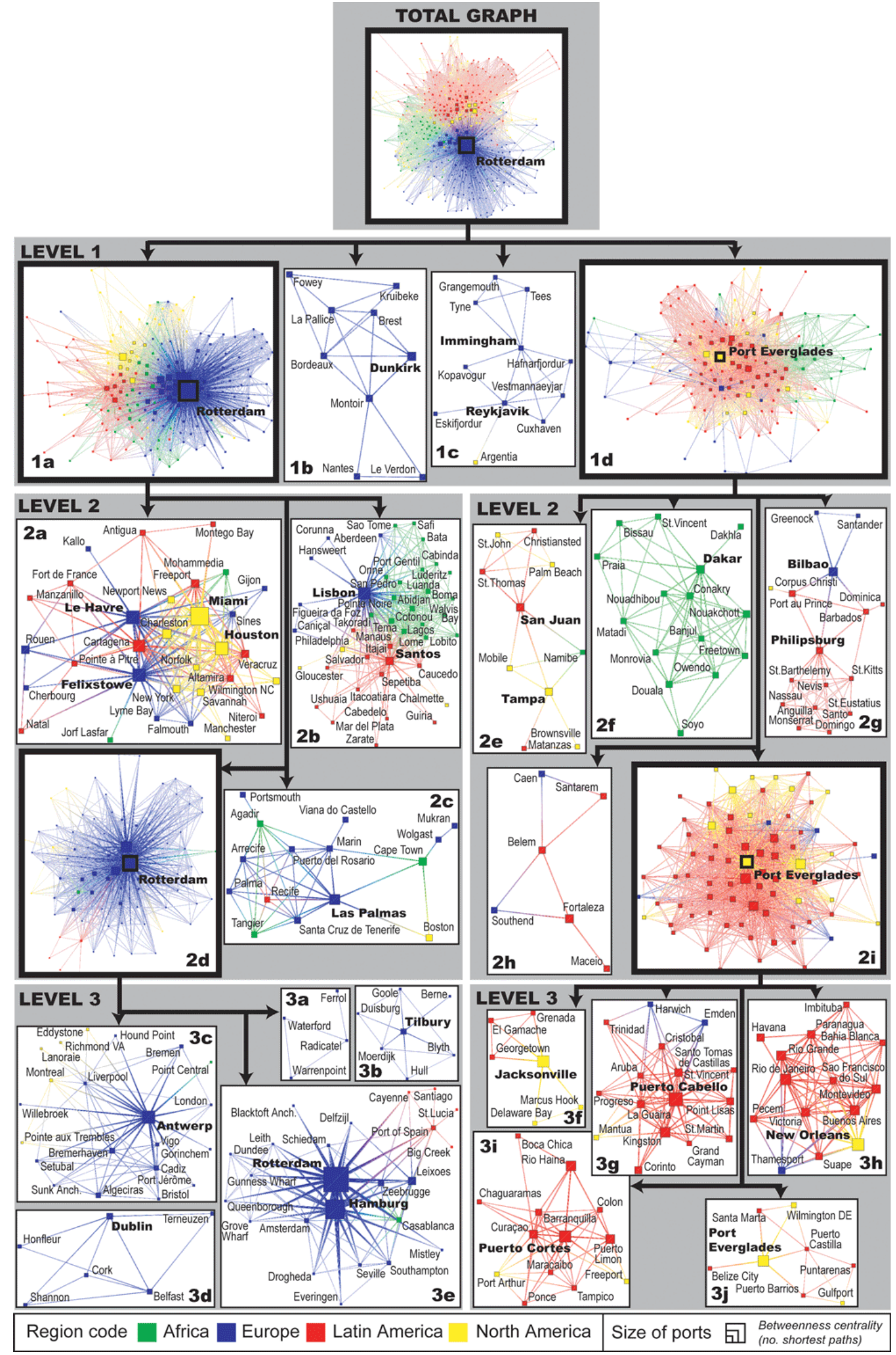

Source: realized by authors based on LMIU data and TULIP software 